\title{
miR-19 is a key oncogenic component of mir-17-92
}

\author{
Virginie Olive, ${ }^{1,5}$ Margaux J. Bennett, ${ }^{1,5}$ James C. Walker, ${ }^{1}$ Cong $M{ }^{1},{ }^{1}$ Iris Jiang, ${ }^{1}$ \\ Carlos Cordon-Cardo, ${ }^{2}$ Qi-Jing $\mathrm{Li}^{3}{ }^{3}$ Scott W. Lowe, ${ }^{4}$ Gregory J. Hannon, ${ }^{4,7}$ and $\mathrm{Lin} \mathrm{He}^{1,6}$ \\ ${ }^{1}$ Division of Cellular and Developmental Biology, Department of Molecular and Cell Biology, University of California at \\ Berkeley, Berkeley, California 94705, USA; ${ }^{2}$ Irving Cancer Research Center, New York, New York 10032, USA; ${ }^{3}$ Department of \\ Immunology, Duke University Medical Center, Durham, North Carolina 27710; ${ }^{4}$ Watson School of Biological Sciences, Cold \\ Spring Harbor Laboratory, Cold Spring Harbor, New York 11724, USA
}

\begin{abstract}
Recent studies have revealed the importance of multiple microRNAs (miRNAs) in promoting tumorigenesis, among which mir-17-92/Oncomir-1 exhibits potent oncogenic activity. Genomic amplification and elevated expression of mir-17-92 occur in several human B-cell lymphomas, and enforced mir-17-92 expression in mice cooperates with $c$-myc to promote the formation of B-cell lymphomas. Unlike classic protein-coding oncogenes, mir-17-92 has an unconventional gene structure, where one primary transcript yields six individual miRNAs. Here, we functionally dissected the individual components of mir-17-92 by assaying their tumorigenic potential in vivo. Using the $E \mu$-myc model of mouse B-cell lymphoma, we identified miR-19 as the key oncogenic component of mir-17-92, both necessary and sufficient for promoting $c$-myc-induced lymphomagenesis by repressing apoptosis. The oncogenic activity of miR-19 is at least in part due to its repression of the tumor suppressor Pten. Consistently, miR-19 activates the Akt-mTOR (mammalian target of rapamycin) pathway, thereby functionally antagonizing Pten to promote cell survival. Our findings reveal the essential role of miR-19 in mediating the oncogenic activity of mir-17-92, and implicate the functional diversity of mir-17-92 components as the molecular basis for its pleiotropic effects during tumorigenesis.
\end{abstract}

[Keywords: Cancer; apoptosis; c-myc; microRNAs; mir-17-92; mir-19]

Supplemental material is available at http://www.genesdev.org.

Received September 8, 2009; revised version accepted October 21, 2009.

MicroRNAs (miRNAs) encode small, regulatory RNAs that control gene expression predominantly through posttranscriptional repression (Ambros 2004; Zamore and Haley 2005; Bartel 2009). Nascent transcripts from miRNA genes (pri-miRNAs) contain one or multiple unique stem-loop structures. Mature miRNAs, ranging from 18 to 24 nucleotides (nt) in length, are initially embedded within one arm of the hairpin stems. These primiRNAs are processed sequentially by the ribonuclease III enzymes Drosha and Dicer to yield the mature miRNA duplexes (Kim et al. 2009). As the mature duplex is formed, the miRNA strand is then incorporated into the RNA-induced silencing complex (RISC) to mediate posttranscriptional regulation of specific mRNAs, primarily through mRNA degradation and/or translational repression (Filipowicz et al. 2008). The target recognition by miRNAs is achieved through imperfect complementarity. The seed region of the mature miRNA (nucleotides

\footnotetext{
${ }^{5}$ These authors contributed equally to this work. Corresponding authors.

${ }^{6}$ E-MAIL lhe@berkeley.edu; FAX (510) 642-9562.

7E-MAIL hannon@cshl.edu; FAX (516) 367-8874.

Article is online at http://www.genesdev.org/cgi/doi/10.1101/gad.1861409.
}

2-8) is often complementary to sites within the target mRNAs, forming a "seed match" in an otherwise imperfect base-pairing (Bartel 2009). The small size of miRNAs, combined with imperfect target recognition, provide miRNAs with the enormous capacity and versatility to act as global gene regulators in diverse developmental and physiological processes. Recent bioinformatic predictions and several experimental validations also suggest that each miRNA is likely to regulate hundreds of mRNA targets and fine-tune their expression in a cell typedependent and context-dependent manner (Baek et al. 2008; Selbach et al. 2008; Chi et al. 2009).

The connection between miRNAs and cancer was first implicated by their frequent genomic alteration and dysregulated expression in various human tumors (Calin et al. 2004; Lu et al. 2005; He et al. 2007b). Multiple miRNAs were subsequently identified to promote or suppress oncogenesis, presumably by modulating gene expression in the oncogenic and tumor suppressor networks (He et al. 2005, 2007a; Johnson et al. 2005; Kumar et al. 2008; Kota et al. 2009). One of the first oncogenic miRNAs identified was mir-17-92 (also known as oncomir-1), a miRNA polycistron with pleiotropic functions in cell 
survival, proliferation, differentiation, and angiogenesis (Hayashita et al. 2005; He et al. 2005; Lu et al. 2005; O'Donnell et al. 2005; Dews et al. 2006; Ventura et al. 2008). mir-17-92 is the primary target of the genomic amplification 13q31 that occurs in Burkitt's lymphoma, diffuse large B-cell lymphoma (DLBCL), mantle cell lymphoma, follicular lymphoma, and several other solid tumor types (Ota et al. 2004; He et al. 2005; Tagawa and Seto 2005; Tagawa et al. 2007; Inomata et al. 2009; Navarro et al. 2009). Additionally, mir-17-92 is highly expressed in a range of hematopoietic malignancies, particularly in B-cell lymphomas (Lu et al. 2005; Tagawa and Seto 2005; Navarro et al. 2009). Although transgenic mice with moderate mir-17-92 overexpression only develop lymphoproliferative phenotypes (Xiao et al. 2008), enforced highlevel expression of mir-17-92, in conjunction with $c$-myc, has potent transformation potential in mouse B cells in vivo, largely due to its ability to repress apoptosis (He et al. 2005) This observation is consistent with the recurring mir-17-92 amplifications in MYC-rearranged Burkitt's lymphomas and DLBCLs in humans (Tagawa et al. 2007). The survival effect of mir-17-92 is also evident in the normal development of the B-cell compartment, as mir17-92 deficiency leads to premature cell death during proB-to-pre-B transition (Ventura et al. 2008).

Unlike classic protein-coding oncogenes, where one transcript generally gives rise to one protein product, the mir-17-92 miRNA cluster produces a single polycistronic primary transcript that yields six individual mature miRNAs. The distinct mature miRNA sequence of these mir-17-92 components dictates the specificity of their target regulation, and ultimately can determine the functional specificity. Here we report the functional dissection of mir-17-92 in the context of B-cell transformation in vivo, and reveal the essential role of $m i R-19$ in medi-

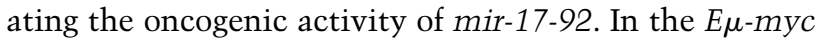
model of Burkitt's lymphoma, miR-19 is both necessary and sufficient for mir-17-92 to promote $c$-myc-induced B lymphomagenesis. The oncogenic activity of $m i R-19$ is at least in part mediated by the PI3K (phosphatidylinositol 3-kinase)-Akt-mTOR (mammalian target of rapamycin) pathway, as enforced miR-19 expression dampens the expression of the tumor suppressor Pten, thus activating the Akt-mTOR signaling to promote cell survival. Our findings demonstrate the functional diversity of mir-17-92 components, and characterize the key molecular mechanism through which the mir-17-92 polycistron promotes malignant transformation in the B-cell compartment.

\section{Results}

mir-17-92 encodes a miRNA polycistron that yields six individual components

The mir-17-92 miRNA cluster produces a single polycistronic primary transcript that yields six mature miRNAs: $m i R-17, m i R-18 a, m i R-19 a, m i R-20 a, m i R-19 b$, and $m i R-92 a$ (Fig. 1A). This unique structural feature of mir-17-92, shared by a large number of miRNA genes in mammalian genomes, may constitute the molecular basis for its pleiotropic functions in a cell type-dependent
A

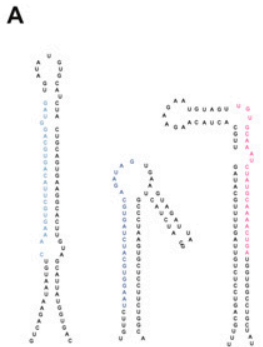

- $17-18 a-19 a+10 a-19 b-11-92 a+1-$

C

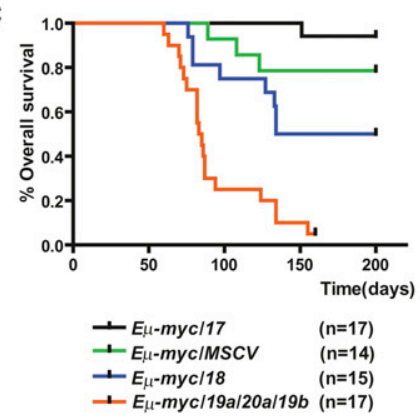

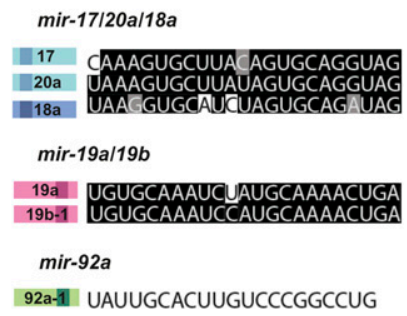

D

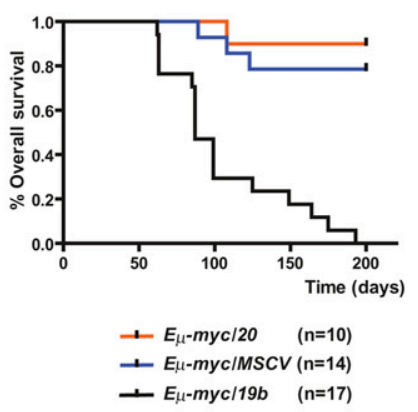

Figure 1. $m i R-19 b$ phenocopies the oncogenic effects of mir-17-92 in the E $\mu$-myc model. (A) Gene structure of the mir-17-92 polycistronic cluster. (Light-colored boxes) Pre-miRNAs; (dark-colored boxes) mature miRNAs. Homologous miRNA components are indicated by the same or similar colors. (B) mir-17-92 components belong to three miRNA families: $m i R-17 / 20 a / 18$ (blue), miR-19 (red), and miR-92a (green). Mature miRNA sequence alignments are shown for each family. Based on sequence identity, $m i R-17$ and $m i R-20 a$ are closely related homologs, sharing significant sequence identity with $m i R-18 a$, but containing a slightly different seed (74\% identity among all three). miR-19a and miR-19b differ by a single nucleotide at position 11 , and are likely to regulate the same mRNA targets ( $96 \%$ identity). miR-92a has a unique seed sequence that distinguishes it from other components. $(C)$ The mir-19a/20/19b subcluster accelerates $c$-myc-induced lymphomagenesis. Irradiated mice reconstituted with the $E \mu-m y c /+$ HSPCs overexpressing miR-17, miR-18a, mir-19a/20a/19b, or a MSCV control vector were monitored weekly beginning 4 wk post-transplantation. The Kaplan-Meier curves represent percentage of overall survival. (D) $m i R-19 b$ accelerates $c$-myc-induced lymphomagenesis. The mir-19a/20/19b subcluster was further divided into $m i R-19 b$ and $m i R-20 a$, each overexpressed in the $E \mu$ myc/+ HSPCs before transplantation into lethally irradiated recipient animals. Reconstituted mice were monitored weekly starting $4 \mathrm{wk}$ post-transplantation. The Kaplan-Meier curve indicates $m i R-19 b$ has a strong oncogenic effect. 
and context-dependent manner. Based on sequence homology, the six mir-17-92 components can be categorized into three miRNA families: $m i R-17 / 20 a / 18 a, m i R-19 a /$ 19b, and miR-92a (Fig. 1B). miR-17 and miR-20a miRNAs are closely related homologs, differing by $2 \mathrm{nt}$ outside the seed sequence (Fig. 1B). A related miRNA miR-18a has a similar yet not identical seed region, but shares significant sequence identity with mir-17/20a overall (Fig. 1B). The second miRNA family contains $m i R-19 a$ and $m i R-$ $19 b$, which differ only by a single nucleotide at position 11 , a region minimally important for target recognition (Fig. 1B; Lewis et al. 2003, 2005; Farh et al. 2005; Grimson et al. 2007). Finally, the unique seed region of $m i R-92 a$ distinguishes it from all of the other mir-17-92 components (Fig. 1B). All six mir-17-92 miRNAs can repress many target mRNAs either cooperatively or individually; both mechanisms could lead to cell type-dependent and context-dependent functional readout.

miR-19 exhibits potent oncogenic activity in the E $\mu$-myc model

Previously, we chose the $E \mu-m y c$ model of Burkitt's lymphoma to evaluate the oncogenic activity of mir-1792 in vivo because genomic amplification and up-regulated expression of mir-17-92 were both observed in human Burkitt's lymphomas (Tagawa et al. 2007). Recent studies also indicated the association between recurring mir-17-92 genomic amplification and MYC rearrangement in Burkitt's lymphomas and DLBCLs, further implicating a functional cooperation between these two lesions (Tagawa et al. 2007). The $E \mu$-myc transgenic mice carry a $c-m y c$ oncogene driven by the immunoglobulin heavy-chain enhancer $(E \mu)$, which is a powerful system in Burkitt's lymphoma. These mice exhibit $c$-myc overexpression specifically in the B-cell lineage, and ultimately acquire late-onset B-cell lymphomas with a latency of $\sim 6$ mo (Adams et al. 1985). To examine the oncogenic potentials of any candidate miRNA, the $E \mu$ - $m y c /+$ hematopoietic stem and progenitor cells (HSPCs) can be infected with murine stem cell viruses (MSCVs) overexpressing the miRNA, and then transplanted into lethally irradiated recipient animals (Supplemental Fig. S1B; Schmitt et al. 2000). The oncogenic potential can be evaluated by the acceleration of $c-m y c$-induced lymphomagenesis in this adoptive transfer model (Supplemental Fig. S1B).

The first evidence that individual mir-17-92 components may contribute differently to its oncogenic potential comes from our previous observation, in which mir17-19b, a truncated mir-17-92 cluster lacking miR-92a (Supplemental Fig. S1A), can greatly accelerate $c-m y c-$ induced tumorigenesis in the E $\mu$-myc model (He et al. 2005). The fact that miR-92a is dispensable for the oncogenic activity prompted us to further divide the mir-17-19b cluster to functionally dissect the oncogenic potentials of each individual miRNA component (Supplemental Fig. S1A).

We initially divided the oncogenic mir-17-19b miRNA polycistron into three subclusters: $m i R-17, m i R-18 a$, and mir-19a/20a/19b (Supplemental Fig. S1A). Overexpres- sion of the control vector (MSCV) or $m i R-17$ in this adoptive transfer model had minimal oncogenic effects, causing late-onset B lymphomas with incomplete penetrance (Fig. 1C). In contrast, animals coexpressing mir$19 a / 20 a / 19 b$ and $c-m y c$ developed highly malignant, early-onset B lymphomas, with a median survival at $84 \mathrm{~d}$ post-transplantation $(P<0.0001, \log$ rank test) (Fig. 1C). Interestingly, $\mathrm{miR}-18 \mathrm{a}$ overexpression caused a moderate acceleration of lymphomagenesis in the $E \mu$-myc model (Fig. 1C). Although it is unlikely that miR-18a is the major oncogenic component of mir-17-19b, it may play accessory roles to facilitate $m i R-19 a / 20 a / 19 b$ to promote malignant transformation in the $E \mu$-myc model. Retroviruses driving mir-17-19b and each of the subclusters had similar levels of overexpression, indicating that the observed difference in oncogenic effects reflected true functional differences among mir-17-92 components, rather than differences in expression level (data not shown).

The three miRNAs encoded by mir-19a/20a/19b belong to two distinct families: $m i R-19$ (including $m i R-19 a$ and $m i R-19 b)$ and miR-20a. While miR-20a exhibited minimal oncogenic collaboration with $c-m y c, m i R-19 b$ and $c$-myc resulted in highly malignant $\mathrm{B}$ lymphomas with nearly complete penetrance (median survival $87 \mathrm{~d}$; $P<0.0001, \log$ rank test) (Fig. 1D). Given the sequence homology between miR-19a and miR-19b and their 1-nt divergence at a region nonessential for miRNA target recognition, it is possible that $m i R-19 a$ can also accelerate $c$-myc-induced lymphomagenesis. Similar to mir-19a/ $20 a / 19 b, \operatorname{miR}-19 b$ phenocopied the oncogenic effects of mir-17-19b. Interestingly, mice overexpressing $m i R-19 b$ exhibited a slightly longer life span after reconstitution (Fig. 3C, below) when compared with those overexpressing $m i R-17-19 b$, a difference likely due to functional cooperation among $m i R-19 b, m i R-19 a$, and possibly $m i R-18 a$.

Histopathological and immunophenotyping analyses confirmed the phenotypic similarities among the $E \mu$ -

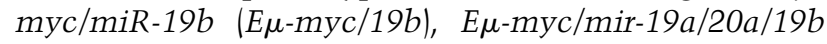

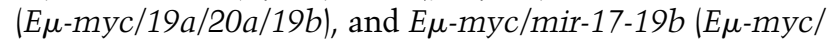
17-19b) lymphomas. These mice developed advanced lymphomas, with massive enlargement of lymph nodes, splenic hyperplasia, and leukemia. In all cases, lymphoma cells invaded the thymus and bone marrow, as well as visceral organs outside the lymphoid compartment, including the liver, lung, and, occasionally, kidney (Fig. 2A; He et al. 2005). While control E $\mu$-myc lymphomas exhibited a high mitotic index accompanied by extensive cell death as shown by TUNEL staining (Fig. $2 B$; Supplemental Fig. S3), the $E \mu-m y c / 19 a / 20 a / 19 b$ and $E \mu-m y c / 19 b$ lymphomas, similar to $E \mu-m y c / 17-19 b$ lymphomas, had greatly reduced apoptosis without affecting cell proliferation (Fig. 2B; Supplemental Fig. S3). Although mir-17-92 has been implicated to promote cell proliferation in other cellular contexts /Ventura et al. 2008), mir-17-19b, mir-19a/20a/19b, and miR-19b overexpression did not enhance cell proliferation in the $E \mu$ myc model. The lack of proliferative effects in the B-lymphoma cells is likely due to the high level of basal proliferation resulting from $c$-myc overexpression. Additionally, control $E \mu$-myc mice frequently develop more 
A
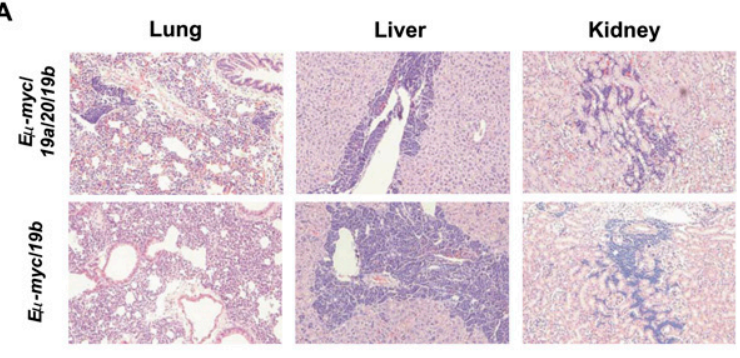

B
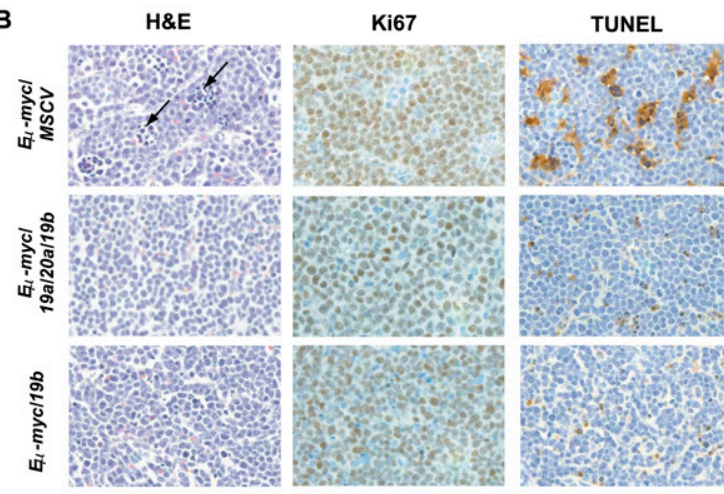

C
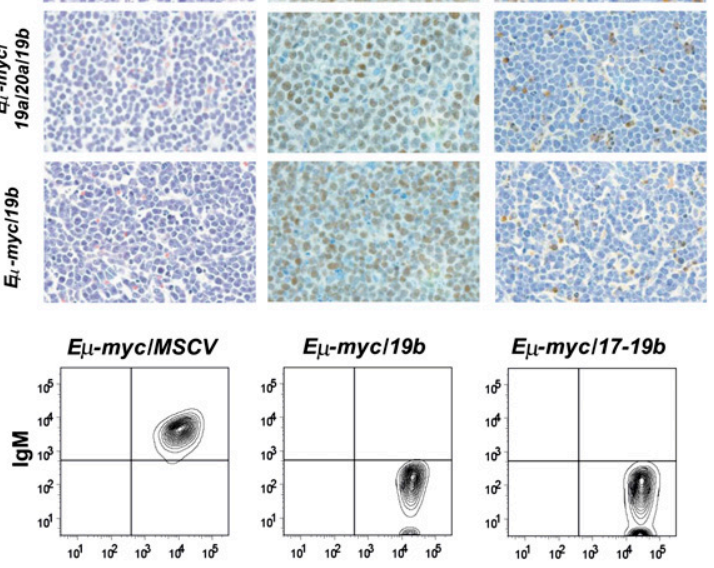

CD19

Figure 2. $E \mu-m y c / 17-19$ and $E \mu-m y c / 19 b$ lymphomas have similar pathological and immunological features. (A) E $\mu$-myc/ $19 b$ lymphomas are highly invasive. H\&E staining of the liver, lung, and kidney showed aggressive invasion by $E \mu-m y c / 19 b$ tumor cells, which was highly analogous to that of the $E \mu$-myc/ $19 a / 20 a / 19 b$ lymphomas. In particular, both perivascular and parenchymal invasion of the liver were observed. $(B)$ Overexpression of $m i R-19 b$ represses $c$-myc-induced apoptosis. The $E \mu-m y c / 19 b$ and $E \mu-m y c / 19 a / 20 a / 19 b$ lymphomas had similar proliferation rates to those of $E \mu$-myc/MSCV controls, demonstrated by Ki67 staining. However, exogenous expression of miR-19b or mir-19a/20/19b greatly decreased apoptosis in the $E \mu$-myc tumors, confirmed by TUNEL and H\&E staining of $E \mu$ myc/17-19 lymph node tumors. The "starry sky" morphology of cell clusters undergoing apoptosis (black arrows), a hallmark of $E \mu$-myc/MSCV lymphomas, was absent in $E \mu$-myc/19b and $E \mu$ myc/19a/20a/19b tumors. (C) miR-19b and mir-17-19b preferably transform progenitor B cells. Flow cytometric immunophenotyping of representative $E \mu-m y c, E \mu-m y c / 17-19$, and $E \mu$-myc/ 19 lymphomas. While the majority of $E \mu$-myc tumors consisted of CD19-positive and IgM-positive B cells, the $E \mu$-myc/19b and $E \mu-m y c / 17-19$ tumor cells bore cellular characteristics of progenitor B cells, positive for CD19 but not for surface IgM.

mature B-cell lymphomas, but the $E \mu$-myc/19b, E $\mu$-myc/ $19 a / 20 a / 19 b$, and $E \mu-m y c / 17-19 b$ tumors were derived primarily from progenitor B cells (Fig. 2C; Supplemental Table S1; Supplemental Fig. S2), suggesting a functional preference for these miRNAs to transform B-cell progenitors under our experimental conditions. These observations were consistent with the B-cell phenotypes in the

mir-17-92 knockout mice, in which the pro-B-to-pre-B transition was marked by extensive apoptosis (Ventura et al. 2008).

\section{miR-19 components are required}

for the oncogenic activity of mir-17-92

Among all of the mir-17-92 components, miR-19 is sufficient for accelerating $c$-myc-induced lymphomagenesis. To determine whether miR-19 miRNAs are also necessary for the oncogenic effects of mir-17-19b, we introduced mutations into $m i R-19 a$ and $m i R-19 b$ within the mir-17-19b construct (designated as mir-17-19bMut19). In so doing, we disrupted the hairpin stem of both $m i R-19 a$ and miR-19b to abolish the biogenesis of miR-19 miRNAs while preventing generation of cryptic miRNAs. These mutations specifically disabled miR-19 biogenesis, without affecting that of miR-17, miR-18a, and miR-20a within the same construct (Fig. 3A,B). Consistent with miR-19 being the key oncogenic component, the miR-19 mutations greatly compromised the oncogenic capacity of mir-17-19b, causing delayed tumor onset, incomplete penetrance, and extended life span (median survival $141 \mathrm{~d} ; P<0.001, \log$ rank test) (Fig. 3C).

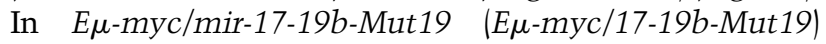
animals that ultimately developed late-onset lymphomas, the miR-19 mutations significantly compromised cell survival without affecting cell proliferation (Fig. 3D,E; Supplemental Fig. S3). In comparison, tumors derived from oncogenic collaboration between $c$-myc and mir-17-19b or miR-19b alone exhibited greatly reduced apoptosis (Figs. 2B, 3D,E). The miR-19 mutations not only disrupted cell survival, but also compromised the ability of mir-17-19b to preferentially transform progenitor B cells. This was suggested by the immunophenotyping analyses on $E \mu$-myc/17-19b-Mut19 B-cell tumors, which exhibited more cell type heterogeneity compared with $E \mu$-myc/17-19b tumors (Supplemental Table S1). Taken together, these findings establish miR-19 miRNAs as the key oncogenic component within mir-17-92, promoting tumorigenesis seemingly through the repression of c-myc-induced apoptosis.

miR-19 specifically dampens the expression level of the tumor suppressor Pten

miR-19 is the key oncogenic component of mir-17-92, and therefore miR-19-specific targets are likely to mediate the oncogenic effects of mir-17-92. Among hundreds of miR-19 targets predicted by TargetScan and RNA22 (Lewis et al. 2005; Miranda et al. 2006; Grimson et al. 2007), the tumor suppressor Pten is a prominent candidate, due to its important functions in promoting apoptosis and tumor suppression. Pten is a negative regulator of the PI3K signaling. In response to a variety of extracellular signals, the PI3K pathway elicits diverse cellular responses to promote cell survival, rapid proliferation, and cell growth. Pten has been implicated as a target of mir-17-92 by luciferase reporter assays and Western analyses in cell culture-based experiments (Takakura 
A
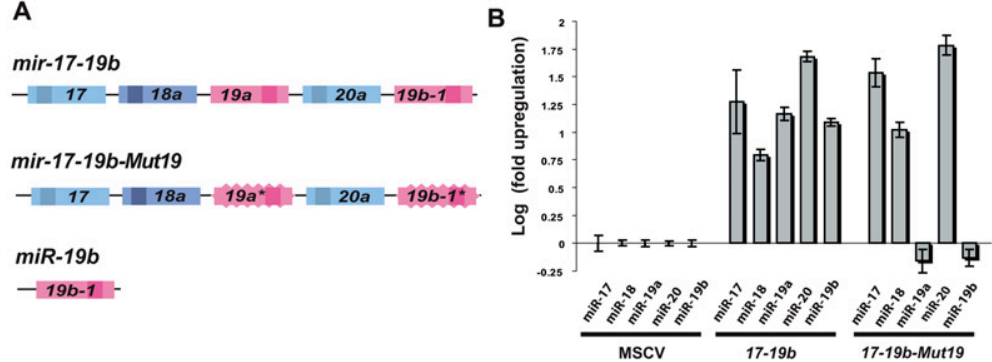

C
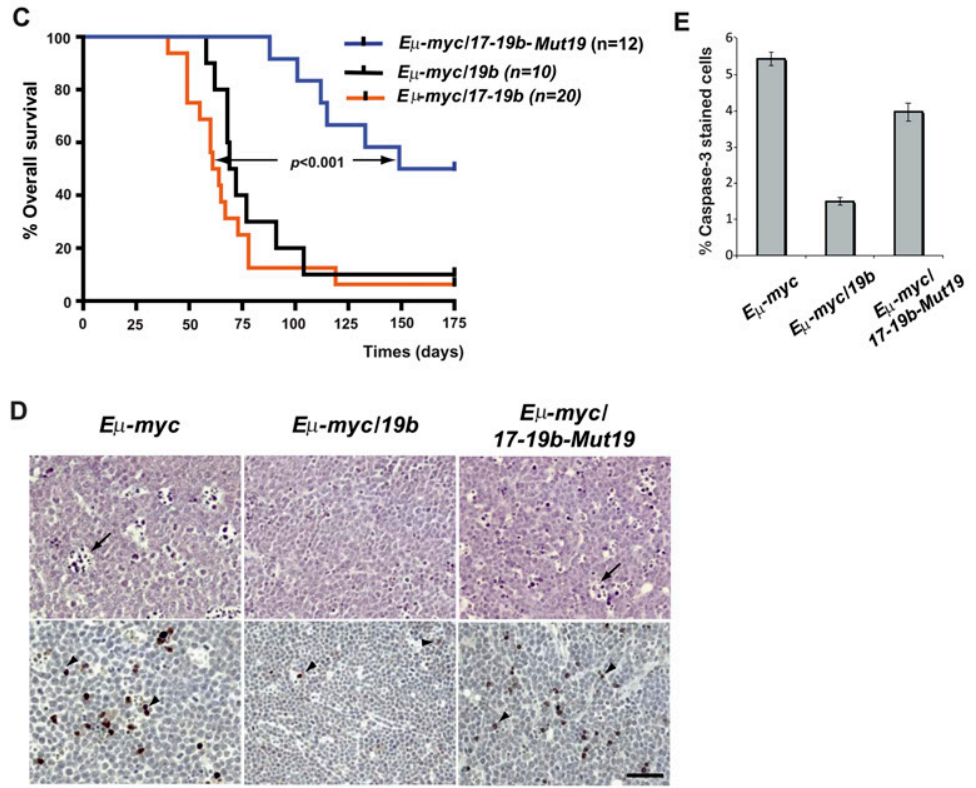

Figure 3. $m i R-19$ miRNAs are essential for the oncogenic activity of mir-17-19b. (A) A schematic representation of the gene structural organization of mir-17-19b, mir-17-19b-Mut19, and miR-19b. 19a * and $19 \mathrm{~b}^{\star}$ indicate $\mathrm{miR}-19$ mutations. (B) miR-19 mutations specifically affected $m i R-19$ expression in mir-17-19b. 3T3 cells were infected with MSCV-mir17-19b, MSCV-mir-17-19b-Mut19, or control MSCV vectors. Expression levels of $m i R-17, m i R-18 a, m i R-$ $19 a, m i R-20 a$, and $m i R-19 b$ were determined using TaqMan miRNA assays. miR-19 mutations specifically affected the expression of $m i R-19 a$ and $m i R$ $19 b$, but not that of the adjacent mir-17-19b components. Error bars indicate SD $(n=3)$. $(C) \operatorname{miR}-19$ is both necessary and sufficient for the oncogenic effect of mir-17-19b. Overexpression of miR-19b and mir$17-19 b$ accelerated $c$-myc-induced lymphomagenesis to a similar degree, shown in Kaplan-Meier curves as the percentage of overall survival. Mutations in $m i R$ 19 greatly decreased the oncogenic activity of mir-17$19 b$ in the $E \mu$-myc model. We compared the oncogenic effects of mir-17-19b, miR-19b, and mir-17-19bMut19 in the same adoptive transfer experiment. (D) miR-19 is both necessary and sufficient for the cell survival effect of mir-17-19b in vivo. Representative lymphomas from $E \mu-m y c, E \mu-m y c / 19 b$, and $E \mu$-myc/ 17-19b-Mut19 were stained for H\&E and caspase-3, which indicated that the miR-19 mutations significantly compromised cell survival effects of mir-17$19 b$, while $\operatorname{miR}-19 b$ overexrepssion suppresses apoptosis. The $E \mu$-myc/19b and $E \mu$-myc/17-19b-Mut19 tumors shown here were both IgM-negative B lymphomas. (Arrow) "Starry sky" feature of apoptotic tumor cells; (arrowhead) apoptotic cells with positive caspase-3 staining. Bar, $50 \mu \mathrm{m}$. (E) Quantification of caspase-3 staining of representative tumors from $D$ as percentage of positive cells. For $E \mu$-myc/19b and $E \mu$-myc/17-19b-Mut19 tumors, only IgM-negative tumors were selected for this comparison ( $n=3$; error bars represent SEM).

et al. 2008; Xiao et al. 2008). However, it is not clear how individual mir-17-92 components contribute to the repression of Pten and, more importantly, whether the down-regulation of Pten by mir-17-92 leads to any functional impact on cell survival.

Overexpression of miR-19b and mir-17-19b-but not miR-17, miR-18a, miR-20a, or MSCV control-significantly down-regulated the endogenous level of Pten mRNA and protein in NIH-3T3 cells (Fig. 4C,D). Similarly, Pten down-regulation by miR-19b and mir-17-19b was observed in mouse primary B-cell culture (Supplemental Fig. S4B). The ability of mir-17-19b to downregulate Pten in both cell types depended on the intact miR-19 components within this cluster, since mir-1719b/Mut19 failed to dampen Pten expression in either 3T3 cells or primary B-cell culture (Fig. 4E,F; Supplemental Fig. S4A,B). These findings suggest that miR-19 is the mir-17-92 component that is both necessary and sufficient to mediate Pten repression. Interestingly, the level of Pten repression by miR-19 was also dependent on cell types and physiological contexts, possibly due to differences in basal levels of miR-19 and Pten expression (Hwang et al. 2009; data not shown).
The human PTEN 3' untranslated region (UTR) contains two miR-19-binding sites (Fig. 4A; Miranda et al. 2006). A luciferase reporter, when fused with the wildtype human PTEN 3'UTR, was significantly repressed by overexpression of $m i R-19 b$, but not by $m i R-17, m i R-18 a$, miR-20a, or miR-1 control (Fig. 4B). Mutations of one or both miR-19-binding sites in the luc-PTEN 3'UTR construct either partially or completely derepressed the luciferase reporter when coexpressed with miR-19b (Fig. $4 \mathrm{~A}, \mathrm{~B})$. These findings suggest that direct binding between miR-19 and PTEN 3'UTR is required for PTEN repression by $m i R-19$.

\section{miR-19 functionally antagonizes Pten to promote cell survival}

miR-19 is evolutionarily conserved across many vertebrate species (Griffiths-Jones 2006). Between Xenopus and mammals, the sequences of miR-19a and miR-19b are identical, and two putative $m i R$-19-binding sites are also present in the Xenopus pten mRNA. These observations implicate a selective pressure to preserve the pten regulation by miR-19 during $\sim 350$ million years of 
Olive et al.

A

\begin{tabular}{|c|c|c|}
\hline PTEN & PTEN & $\simeq \Omega$ \\
\hline Luc-PTEN3'UTR & Luciferase & $\simeq$ \\
\hline LUC-PTEN3'UTR 11 & Luciferase & $\bumpeq$ \\
\hline & Luciferase & \\
\hline Luc-PTEN3'UTR $\triangle 1 \triangle 2$ & & * \\
\hline
\end{tabular}

B

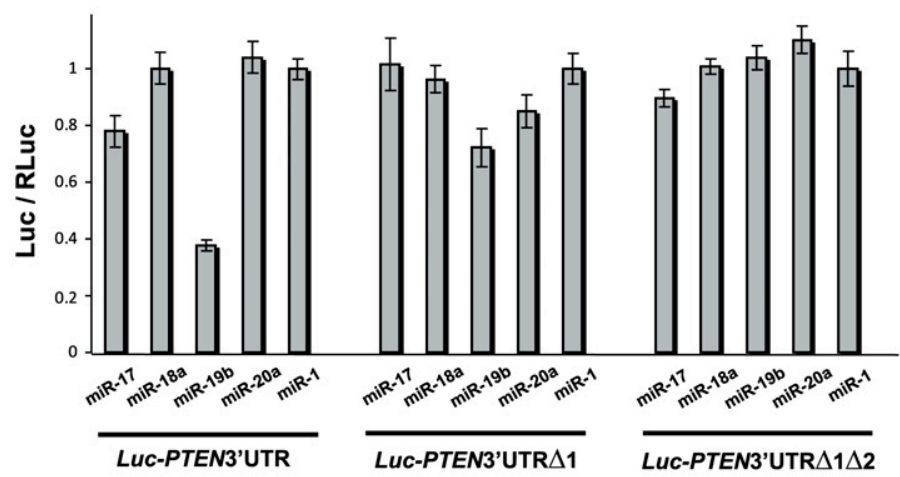

C

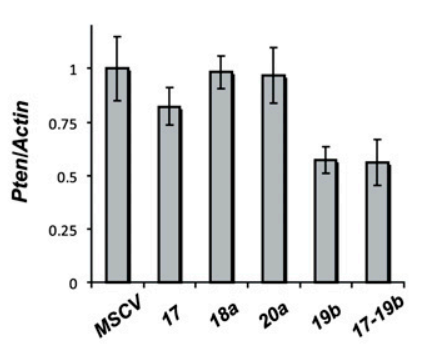

D

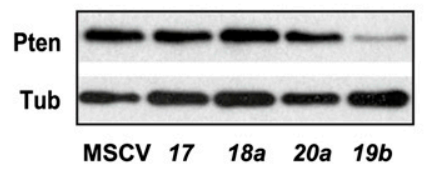

E

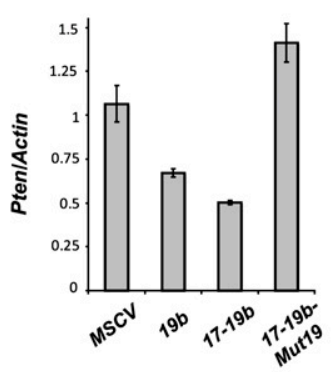

$\mathbf{F}$

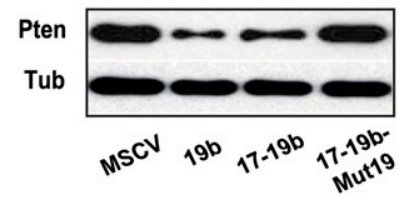

Figure 4. Pten is a mir-17-19b target specifically regulated by $m i R-19$. (A) Schematic representation of the PTEN 3'UTR and its miR-19-binding sites. Two miR-19-binding sites (shown in red) can be found in the human PTEN 3'UTR. The PTEN 3'UTR with mutations (designated with asterisks) at one (PTEN3' UTR $\Delta 1$ ) or both (PTEN3'UTR $\Delta 1 \Delta 2)$ miR-19 sites, as well as the wild-type counterpart (PTEN3'UTR), were each cloned downstream from a luciferase reporter (Luc). (B) Specific repression of Luc-PTEN3'UTR reporter by miR-19. Luc-PTEN3'UTR was cotransfected with mimics of $m i R-17, \operatorname{miR}-18 a, m i R-19 b, m i R-20 a$, and control $m i R-1$. Only $m i R-19 b$ significantly repressed the reporter expression. Cotransfection with a luciferase construct carrying one mutated miR-19b site in the PTEN 3'UTR (Luc-PTEN3'UTR $\Delta$ 1) partially derepressed the Luc reporter, and cotransfection of a construct with mutations in both miR-19 sites (LucPTEN3'UTR $\Delta 1 \Delta 2$ ) completely derepressed the Luc reporter. $(C, D)$ miR-19b specifically represses endogenous Pten expression level. Using real-time PCR analysis $(C)$ and Western analysis $(D)$, down-regulation of endogenous Pten mRNA and protein can be detected in serum-starved NIH-3T3 cells infected with $m i R-19 b$ and mir-17-19b. In comparison, overexpression of $m i R-17, m i R-18 a, m i R-20 a$, and control vector (MSCV) in these cells has minimal effects on the endogenous Pten level. $(E, F)$ miR-19 is both necessary and sufficient to mediate the Pten repression by mir17-19b. Repression of endogenous Pten mRNA $(E)$ and protein $(F)$ can be detected in serum-starved NIH-3T3 cells infected with miR-19b and mir-17-19b. In comparison, mir-17-19b-Mut19 failed to repress the endogenous Pten level. evolution. To determine whether Pten down-regulation by $m i R-19$ had any functional impact, we examined their functional interaction using an in vivo apoptosis assay in Xenopus embryos.

Not only is $m i R-19$ conserved at the sequence level in Xenopus, its anti-apoptotic function is also preserved, evident by its ability to repress hydroxyurea-induced cell death. When subjected to hydroxyurea treatment, Xenopus embryos undergo apoptosis, often characterized by a whitish color, cell blebbing, and disruption of cell adhesion after the mid-blastula transition (Walker and Harland 2009). Injection of $m i R-19 b$ considerably rescued hydroxyurea-induced apoptosis (Fig. 5A,B). Consistent with Pten being a key target of miR-19, injection of $m i R-19$ and pten individually gave rise to opposite phenotypes, with miR-19 promoting cell survival (Fig. 5A,B) and pten inducing apoptosis (Fig. 5C,D). Coinjection of miR-19b and pten, however, significantly rescued pteninduced apoptosis, but a mutated miR-19b (mut-19b) with an altered seed sequence failed to impact the pten function (Fig. 5C,D). When we introduced mutations in the two miR-19-binding sites in the pten cDNA without affecting pten protein coding, the mutated pten mRNA (pten-mut) retained the ability to potently induce cell death. In this case, $m i R-19$ injection failed to rescue the apoptotic effects of pten-Mut (Fig. 5E,F). Altogether, our findings indicate that the repression of Pten by $m i R-19$ occurs not only at the expression level, but also at the functional level, both of which are dependent on the intact miR-19-binding sites within the Pten mRNA.

\section{miR-19 activates the Akt-mTOR pathway} both in vitro and in vivo

PTEN is a tumor suppressor that is mutated or deleted in multiple tumor types with high frequency (Di Cristofano and Pandolfi 2000; Knobbe et al. 2008). It acts to repress the intracellular level of phosphatidylinositol-3,4,5-trisphosphate 
A
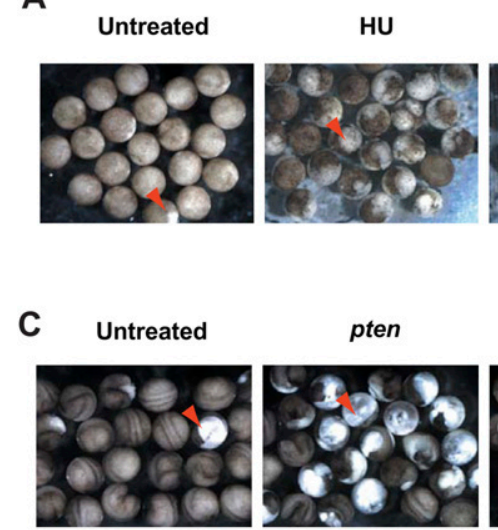

E
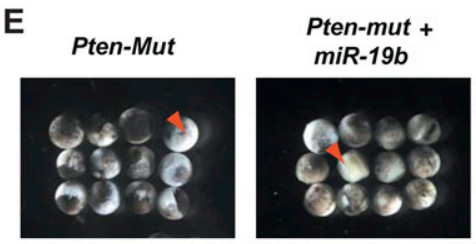
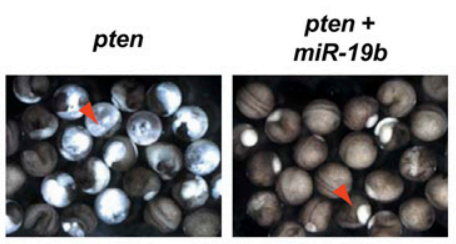
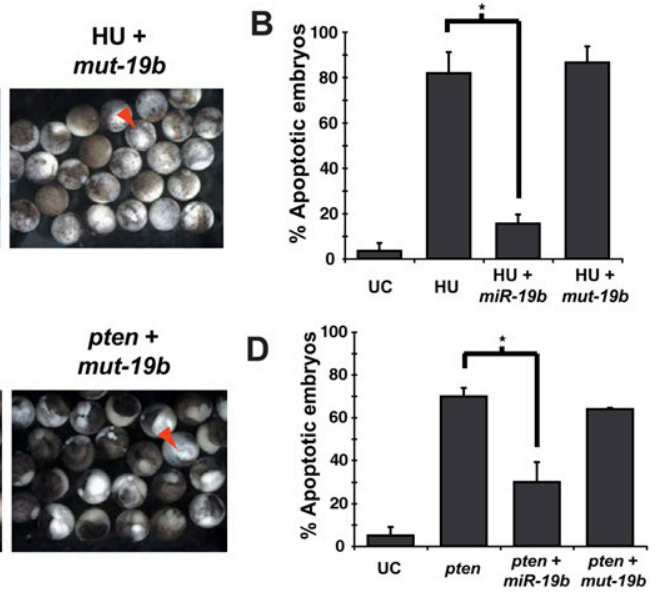

$\mathbf{F}$

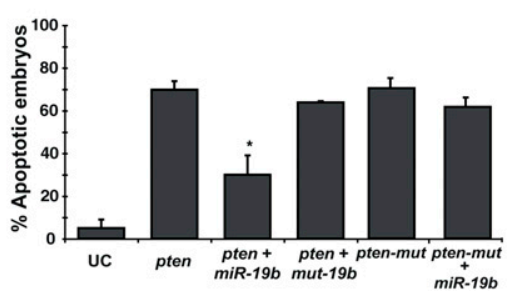

Figure 5. miR-19b functionally antagonizes pten-induced apoptosis in Xenopus embryos. $(A, B)$ miR-19b rescues hydroxyurea (HU)induced apoptosis in $X$. laevis embryos. Injection of miR-19b mimics into X. laevis embryos rescued apoptosis caused by hydroxyurea treatment. The mutated $m i R-19 b$ with an altered seed region $(m u t-19 b)$ failed to rescue hydroxyurea-induced apoptosis. Embryos undergoing apoptosis were marked by cell blebbing, disruption of cell adhesion, and a characteristic white color (red arrowhead). Hydroxyurea-treated embryos appeared more pigmented than control embryos, largely due to developmental arrest. $(B)$ Apoptosis was quantified for untreated and hydroxyurea-treated embryos, as well as the hydroxyurea-treated embryos coinjected with either $m i R-19 b$ mimics or mut-19b mimics $\left(n=3\right.$ experiments with $>25$ embryos in each group; $\left.\left[{ }^{\star}\right] P<0.05\right)$. $(C, D)$ Injection of miR-19b rescued pteninduced apoptosis in Xenopus embryos. Injection of full-length pten mRNA into Xenopus embryos led to widespread apoptosis. Injection of miR-19b, but not mut-19b, significantly rescued the proapoptotic effect of pten. $(E, F)$ Disruption of base-pairing between miR-19 and pten mRNA abolished their functional antagonism. Mutations in the miR-19-binding sites within the pten mRNA (ptenmut) did not abrogate the proapoptotic effects of pten, but did eliminate the ability of miR-19b to repress the apoptosis ( $n=3$ experiments with $>25$ embryos in each group; $\left.\left[{ }^{\star}\right] P<0.05\right)$. All error bars represent SEM.

in cells, thus negatively regulating the PI3K pathway and its downstream effectors, Akt and mTOR (Comer and Parent 2002; Rossi and Weissman 2006). Consistent with the ability of miR-19 to repress Pten expression and function, miR-19b overexpression in NIH-3T3 cells specifically activated the PI3K pathway, leading to increased phosphorylation of Akt without affecting the overall level of Akt (Fig. 6A). miR-19b or mir-17-19b overexpression also caused a significant increase in phosphorylation of S6 ribosomal protein due to the activated mTOR pathway (Supplemental Fig. S4D). Surprisingly, $m i R-17$ and miR-20a overexpression slightly increased the phospho-S6 level compared with the vector control, but this increase might be achieved through a mechanism independent of Pten or Akt (Fig. 6A,B). Using Western analyses and immunohistochemistry assays, a high level of phospho-S6 protein was observed in a cohort of $E \mu$ $m y c / 19 b$ and $E \mu-m y c / 17-19 b$ tumors, suggesting that miR-19 and mir-17-19b were able to activate the mTOR pathway in vivo (Fig. 6C,D), at least in part through the repression on Pten. In comparison, the control E $\mu$-myc tumors generally exhibited a low level of phospho-S6 protein, although a certain degree of heterogeneity existed among different tumors. Although mir-17-19b and $m i R-19 b$ were equally potent in inducing phospho-S6 in vitro (Supplemental Fig. S4D), the effect of mir-17-19b in vivo was more potent (Fig. $6 \mathrm{C}, \mathrm{D}$ ), possibly due to a degree of cooperative effects from the other miRNA components. The late-onset $E \mu$-myc/17-19b-Mut19 lymphomas had varying levels of phospho-S6, yet this cohort of lymphomas as a whole exhibited a decrease in the phosphoS6 level compared with $E \mu$-myc/17-19b tumors (Supplemental Fig. S4E).

Although Pten deficiency in mice frequently gives rise to T-cell malignancy, Pten heterozygosity appears to partially phenocopy mir-17-19b overexpression, and cooperates with $c$-myc in the $E \mu$-myc model to moderately accelerate B lymphomagenesis (Wendel et al. 2006). However, the oncogenic effect of miR-19b or mir-17$19 b$ is more potent than Pten heterozygosity in the $E \mu$ myc lymphoma model. Pten is a haploinsufficient tumor suppressor whose dosage proportionally impacts its tumor suppressor activity and inversely correlates with tumor progression in a cell type-dependent manner 
Olive et al.

A

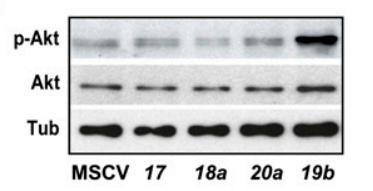

B

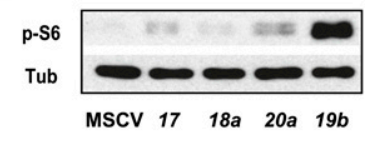

C

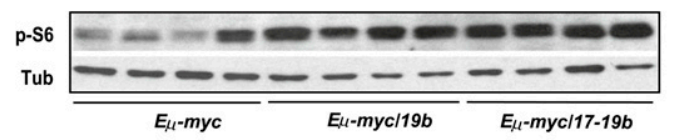

D

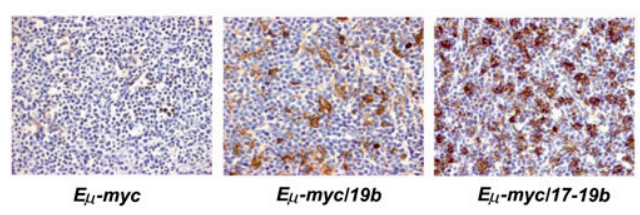

Figure 6. miR-19 and mir-17-19b activates the Akt-mTOR pathway. (A) miR-19 is a key mir-17-19b component to activate the Akt-mTOR pathway. Using Western analysis, increased phospho-Akt level was detected in serum-starved 3T3 cells infected with $m i R-19 b$, but not $m i R-17, m i R-18 a, m i R-20 a$, and the control vector (MSCV). In comparison, the overall Akt level was not affected by miR-19b. (B) miR-19 induces an increase in phosphorylation of S6 ribosomal protein. Enforced expression of $m i R-19 b$ strongly promoted the S6 phosphorylation as compared with the rest of mir-17-19b components. $(C, D)$ Enforced $m i R-19 b$ or mir-17-19b expression in the $E \mu-m y c$ model led to an increased level of phospho-S6 in lymphomas. Cells derived from the $E \mu-m y c, E \mu-m y c / 19 b$, and $E \mu-m y c / 17-$ $19 b$ lymphomas were analyzed by Western $(C)$ and immunohistochemistry $(D)$. Both $E \mu$-myc/19b and $E \mu$-myc/17-19b lymphomas exhibited a high level of phospho-S6, although mir-17-19b seemed to have a stronger effect. In comparison, $E \mu$-myc tumors exhibited a low level of phospho-S6 and more variation among different samples, possibly reflecting the differences in the secondary oncogenic lesions. In all Western analyses, tubulin (Tub) was used as a normalization control.

(Trotman et al. 2003). It is likely that $m i R-19 b$ or mir-17$19 b$ overexpression, when compared with Pten heterozygosity, causes greater Pten repression (Supplemental Fig. $\mathrm{S} 4 \mathrm{C})$, and thus a stronger B-cell transformation in the $E \mu$-myc model. Interestingly, in non-Hodgkin's B-cell lymphomas (NHLs) including Burkitt's lymphoma and DLBCL, recurring deletions and rearrangements of 10q23, which harbors PTEN, are observed in $5 \%-10 \%$ of patients (Butler et al. 1999). In addition, the reduction or loss of PTEN expression is often associated with inferior survival (Abubaker et al. 2007; Robledo et al. 2009). These findings implicate the importance of the PTEN pathway in the progression and prognosis of specific human B-cell malignancies. Besides PTEN deletion and mutations, mir17-92-mediated PTEN repression may be an additional mechanism to disrupt the PTEN function and to promote malignant transformation in human B cells. In line with this hypothesis, a recent study described a subset of DLBCLs in which the amplification of mir-17-92 and the deletion of PTEN are mutually exclusive (Lenz et al. 2008).

\section{Discussion}

The small size of miRNAs, combined with their imperfect base-pairing for target recognition, allows miRNAs to regulate many mRNA targets. The strong cooperation between $m i R-19$ and $c-m y c$ can result from the collective impacts on many miR-19 targets, of which Pten is a key target, but it may not be the only one. Given the robust induction of phospho-S6 by $m i R-19$, it is possible that other negative regulators of the PI3KAKT-mTOR pathway, in addition to Pten, are coordinately regulated. It is also conceivable that additional pathways regulated by $m i R-19$ could synergize with down-regulated Pten to promote cell survival and malignant transformation. Increasing evidence suggests that the dosage of tumor suppressor genes has a significant impact on their functional readout. A number of tumor suppressors are haploinsufficient, and hypomorphic mutations in tumor suppressors are frequent in cancer (Payne and Kemp 2005). Given the importance of miRNAs in human cancer and their unique mechanism of action, partial repression of tumor suppressors is likely a novel mechanism through which miRNA oncogenes promote malignant transformation.

Polycistronic gene structure is frequently observed in miRNA loci (Ambros 2004; He and Hannon 2004; Zamore and Haley 2005). Since each miRNA has the potential to regulate hundreds of target mRNAs, a miRNA polycistron containing multiple components may possess a greater capacity for gene regulation, thus yielding pleiotropic biological effects through complex mechanisms of coordination. In the context of B-cell transformation in the $E \mu-m y c$ model, $m i R-19$ miRNAs are identified as the key oncogenic components of mir-17-92 to cooperate with $c$-myc. The other mir-17-92 components either are dispensable for oncogenesis, or, as in the case of $m i R-18 a$, may play an accessory role to enhance oncogenic potential. As a strong oncogene, mir-17-92 can regulate multiple cellular processes to favor malignant transformation, causing decreased cell death, rapid cell proliferation, and increased angiogenesis (He et al. 2005; O'Donnell et al. 2005; Dews et al. 2006; Ventura et al. 2008). However, it remains unclear how this polycistronic miRNA regulates coordinated biological processes to achieve malignant transformation. It is conceivable that individual mir-1792 components function cooperatively to impact multiple cellular processes, although more complex mechanisms of coordination may also exist. A recent study indicates that $m i R-17$ overexpression in mice decreases cell proliferation, adhesion, and migration, raising a possibility that components of mir-17-92 can both positively and negatively regulate the same cellular process to achieve homeostasis (Shan et al. 2009). It is possible that cell types and biological contexts may also determine the exact mechanisms of coordination among polycistronic miRNA components. We are just beginning to understand the functional complexity of polycistronic miRNAs, which have an enormous capacity for gene regulation and complex coordination among different components. The unique gene structure of these miRNA polycistrons 
can ultimately underlie the molecular basis for their pleiotropic functions in the oncogenic and tumor suppressor network.

\section{Materials and methods}

\section{Molecular construction of mir-17-92 subclusters}

The subclusters of mir-17-92 were amplified by PCR and subsequently cloned into the XhoI and EcoRI sites of the MSCV retrovirus vectors. In these vectors, miRNAs were placed downstream from the LTR promoter, which is followed by either a SV40-GFP cassette (for all in vivo experiments) or a PGK-Puro-Ires-GFP cassette (for all in vitro experiments) (Hemann et al. 2005). To construct the MSCV-17-19b/Mut19 vector, a 12-nt mutation was introduced into the hairpin stem of pre-mir-19a and premir-19b using the QuickChangeXL mutagenesis kit (Strategene). For the MSCV-17-19b/Mut19 vector, the loss of miR-19 expression and the normal expression of the other mir-17-19b components were validated using the TaqMan miRNA assays (Applied Biosystems).

\section{Adoptive transfer of $\mathrm{E} \mu$-myc HSPCs for lymphomagenesis}

Fetal liver-derived HSPCs were isolated from embryonic day 13.5-15.5 (E13.5-E15.5) E $\mu$-myc/+ embryos, and were transduced with MSCV alone or MSCV expressing various mir-17-92 subclusters. The MSCV retroviral vector used in our studies contains a SV40-GFP cassette that allows us to monitor transduced HSPCs both in vitro and in vivo. Infected HSPCs were subsequently transplanted into 8- to 9-wk-old, lethally irradiated C57BL/6 recipient mice. Tumor onset was subsequently monitored by weekly palpation, and tumor samples were either collected into formalin for histopathological studies, or prepared as single-cell suspension for FACS analysis.

\section{Luciferase assays}

Human PTEN 3'UTR were amplified from the genomic DNA (forward primer, 5'-CACCAAGATGGCACTTTCC CGTTT-3'; reverse primer, 5'-TGGCAAACATGTTCAA GAGGAGCT-3'), which contains two miR-19-binding sites that are also conserved in mice. Mutagenesis of these two miR-19-binding sites was carried out using the QuickChangeXL mutagenesis kit (Strategene). The wildtype PTEN 3'UTR, as well as the mutated PTEN 3'UTR fragments, were each cloned downstream from a firefly luciferase reporter. These firefly luciferase constructs that contain either the wild-type or the mutated PTEN 3'UTR were each transfected into the Dicer-deficient Hct116 cells (Cummins et al. 2006), together with a Renilla luciferase construct for normalization control, and $50 \mathrm{nM}$ miRNA mimics for mir-17, mir-18, miR-19b, miR-20a, and mir-1, respectively. These miRNA mimics were generated by annealing two complementary RNA oligos (IDT). Luciferase activity of each construct was determined by dual luciferase assay (Promega) $48 \mathrm{~h}$ posttransfection.

\section{Cell culture}

NIH-3T3 cells were cultured in DMEM with $10 \%$ bovine serum, and were kept $30 \%-40 \%$ confluent throughout the entire cell culture experiment. Primary B cells were prepared from mouse bone marrows, and were cultured in RPMI medium with $10 \%$ fetal bovine serum (FBS), $50 \mu \mathrm{M}$ $\beta$-mercaptoethanol, and $2 \mathrm{ng} / \mathrm{mL}$ Il-7. NIH-3T3 cells and mouse primary B-cell cultures were infected by MSCV retroviruses expressing mir-17-92 subclusters, and were selected by puromycin for $2 \mathrm{~d}$. Serum-starved NIH-3T3 cells were prepared by incubating the cells with DMEM without serum for $12 \mathrm{~h}$ before harvesting the cell lysate. MSCV-infected primary B cells were sorted based on GFP, and were then subjected to Western analyses or real-time PCR analyses as described below.

\section{Real-time PCR analysis and Western analysis}

TaqMan miRNA assays (Applied Biosystems) were used to measure the level of mature miRNAs. The mRNA level for Pten (forward primer, 5'-CACAATTCCCAGTC AGAGGCGC-3'; reverse primer, 5'-GCTGGCAGACCA CAAACTGAGGA-3') was determined using real-time PCR analysis with SYBR (Applied Biosystems). Actin was used as a normalization control in all our RT-QPCR experiments (forward primer, 5'-GATCTGGCACCACA CСTTCT-3'; reverse primer, 5'-GGGGTGTTGAAGGT CTCAAA-3'). For Western analyses, Pten (Cell Signaling), Akt (Cell Signaling), phospho-Akt (Ser473; Cell Signaling), and phospho-S6 (Cell Signaling) antibodies were used at 1:1000, and tubulin antibody (Sigma) was used at $1: 4000$.

\section{Histopathology}

Tissue samples were fixed in formalin, embedded in paraffin, sectioned into 5- $\mu \mathrm{m}$ sections, and stained with haematoxylin and eosin (H\&E). For Ki-67 (rabbit antiKi67; NovoCastra), caspase-3 (AF835; R\&D Systems), and PCNA (MS-106P; Lab Vision Corp.) detection, representative sections were deparaffinized and rehydrated in graded alcohols before being subjected to antigen retrieval treatment in a vegetable steamer. Detection of antibody staining was carried out following standard procedures from the avidin-biotin immunoperoxidase methods. Diaminobenzidine (Invitrogen) was used as the chromogen and haematoxylin was used as the nuclear counterstain. Analysis of the apoptotic rate by TUNEL assay was performed according to a published protocol (Di Cristofano et al. 1998).

\section{Flow cytometry}

Lymphoma cells harvested from the animals were resuspended in $10 \% \mathrm{FBS} /$ phosphate-buffered saline (PBS) to reach a concentration of $10^{7}$ cells per milliliter. Twenty microliters of the cell suspension were stained with various antibodies diluted in 10\% FBS/PBS for $1 \mathrm{~h}$. Subsequently, cells were washed with $2 \%$ FBS/PBS and resuspended in $10 \%$ FBS/PBS for flow cytometry analysis. Antibodies 
used for our FACS analyses include PE anti-mouse IgM (eBioscience, 12-5790), APC-Cy7 B220 (BD Pharmingen, 552094), CD4 APC-Cy7 (BD Pharmingen, 552051), PECD8 (BD Pharmingen, 553032), PE-CD25 (BD Pharmingen, 553866), and APC-CD19 (Biolegend, 115511).

\section{Apoptotic assays}

Xenopus laevis eggs were collected and fertilized, and embryos were cultured by standard procedures. The $m i R$ $19 \mathrm{~b}$ mimics were produced from the annealing products of 5'-UGUGCAAAUCCAUGCAAAACUGA-3' and 5'AGUUUUGCAGGUUUGCAUCCAUU-3' (IDT). Two complimentary RNA oligos were combined and diluted to a stock concentration of $1 \mu \mathrm{g} / \mu \mathrm{L}$, heated for $1 \mathrm{~min}$ to $80^{\circ} \mathrm{C}$, and then allowed to cool to room temperature to form duplexes. The same was done to generate the mutated miR-19 mimics, mut-19b, using 5'-UCAGGU AAUCCAUGCAAAACUGA-3' ${ }^{\prime}$ and $5^{\prime}$-AGUUUUGCAG GUUACCUUCGAUU-3'. The Pten-mut construct was made by two consecutive QuickChange reactions of accession plasmid BC161129 with primers 5'-ACAAATT TAGCTGCAGAGTAG-3' and 5'-GGTCTTCAAACGG ATACTGAG-3', and 5'-GCAGAGTGAGGGGAGCGG GT-3' and 5'-CGGGGAAAGGTTGGCACCCG-3'. Xenopus tropicalis pten and pten-mut RNAs were made using the mMessage SP6 kit (Ambion) on Not1-cut plasmid. Embryos were injected into both cells at the two-cell stage with 2 ng of each RNA. Hydroxyurea (Sigma) was diluted to a final concentration of $15 \mathrm{mM}$ and embryos were treated from $2 \mathrm{~h}$ post-fertilization until stage 10.5. All embryos undergoing apoptosis of any cells were scored as positive.

\section{Acknowledgments}

We thank B. Zude, A. Basila, Y. Choi, and K. Lehet for technical assistance, and A. Winoto, D. Raulet, G. Barton, L. Coscoy, J. Liu, and R. Vance for stimulating discussions and helpful input. We also thank M. Schlissel and G.S. Martin for careful reading of our manuscript, and J.M. Silva, A. Economides, M. Schlissel, C. Miething, A. Thomas-Tikhonenko, D. Schulz, P. Garcia, M. Sohaskey, D. Stafford, M. Tokuyama, K. Chow, E. Cadera, W. Cousin, L.C. Trotman, and E. Hernando for sharing reagents and helpful discussions. We are particularly grateful to M. Schriok and B. Colpo for unconditional support. L.H. is a Searle Scholar, and is supported by the pathway to independence grant, an RO1 grant from the NCI, and the new faculty award from CIRM. S.W.L. and G.J.H. are both HHMI investigators, and are supported by a program project grant from the NCI.

\section{References}

Abubaker J, Bavi PP, Al-Harbi S, Siraj AK, Al-Dayel F, Uddin S, Al-Kuraya K. 2007. PIK3CA mutations are mutually exclusive with PTEN loss in diffuse large B-cell lymphoma. Leukemia 21: 2368-2370.

Adams JM, Harris AW, Pinkert CA, Corcoran LM, Alexander WS, Cory S, Palmiter RD, Brinster RL. 1985. The c-myc oncogene driven by immunoglobulin enhancers induces lymphoid malignancy in transgenic mice. Nature 318: 533-538.

Ambros V. 2004. The functions of animal microRNAs. Nature 431: 350-355.
Baek D, Villen J, Shin C, Camargo FD, Gygi SP, Bartel DP. 2008. The impact of microRNAs on protein output. Nature 455: 64-71.

Bartel DP. 2009. MicroRNAs: Target recognition and regulatory functions. Cell 136: 215-233.

Butler MP, Wang SI, Chaganti RS, Parsons R, Dalla-Favera R. 1999. Analysis of PTEN mutations and deletions in B-cell non-Hodgkin's lymphomas. Genes Chromosomes Cancer 24: 322-327.

Calin GA, Sevignani C, Dumitru CD, Hyslop T, Noch E, Yendamuri S, Shimizu M, Rattan S, Bullrich F, Negrini M, et al. 2004. Human microRNA genes are frequently located at fragile sites and genomic regions involved in cancers. Proc Natl Acad Sci 101: 2999-3004.

Chi SW, Zang JB, Mele A, Darnell RB. 2009. Argonaute HITSCLIP decodes microRNA-mRNA interaction maps. Nature 460: 479-486.

Comer FI, Parent CA. 2002. PI 3-kinases and PTEN: How opposites chemoattract. Cell 109: 541-544.

Cummins JM, He Y, Leary RJ, Pagliarini R, Diaz LA Jr, Sjoblom T, Barad O, Bentwich Z, Szafranska AE, Labourier E, et al. 2006. The colorectal microRNAome. Proc Natl Acad Sci 103: 3687-3692.

Dews M, Homayouni A, Yu D, Murphy D, Sevignani C, Wentzel E, Furth EE, Lee WM, Enders GH, Mendell JT, et al. 2006. Augmentation of tumor angiogenesis by a Myc-activated microRNA cluster. Nat Genet 38: 1060-1065.

Di Cristofano A, Pandolfi PP. 2000. The multiple roles of PTEN in tumor suppression. Cell 100: 387-390.

Di Cristofano A, Pesce B, Cordon-Cardo C, Pandolfi PP. 1998. Pten is essential for embryonic development and tumour suppression. Nat Genet 19: 348-355.

Farh KK, Grimson A, Jan C, Lewis BP, Johnston WK, Lim LP, Burge CB, Bartel DP. 2005. The widespread impact of mammalian microRNAs on mRNA repression and evolution. Science 310: 1817-1821.

Filipowicz W, Bhattacharyya SN, Sonenberg N. 2008. Mechanisms of post-transcriptional regulation by microRNAs: Are the answers in sight? Nat Rev Genet 9: 102-114.

Griffiths-Jones S. 2006. miRBase: The microRNA sequence database. Methods Mol Biol 342: 129-138.

Grimson A, Farh KK, Johnston WK, Garrett-Engele P, Lim LP, Bartel DP. 2007. MicroRNA targeting specificity in mammals: Determinants beyond seed pairing. Mol Cell 27: 91-105.

Hayashita Y, Osada H, Tatematsu Y, Yamada H, Yanagisawa K, Tomida S, Yatabe Y, Kawahara K, Sekido Y, Takahashi T. 2005. A polycistronic microRNA cluster, miR-17-92, is overexpressed in human lung cancers and enhances cell proliferation. Cancer Res 65: 9628-9632.

He L, Hannon GJ. 2004. MicroRNAs: Small RNAs with a big role in gene regulation. Nat Rev Genet 5: 522-531.

He L, Thomson JM, Hemann MT, Hernando-Monge E, Mu D, Goodson S, Powers S, Cordon-Cardo C, Lowe SW, Hannon GJ, et al. 2005. A microRNA polycistron as a potential human oncogene. Nature 435: 828-833.

He L, He X, Lim LP, de Stanchina E, Xuan Z, Liang Y, Xue W, Zender L, Magnus J, Ridzon D, et al. 2007a. A microRNA component of the p53 tumour suppressor network. Nature 447: 1130-1134.

He L, He X, Lowe SW, Hannon GJ. 2007b. microRNAs join the p53 network-Another piece in the tumour-suppression puzzle. Nat Rev Cancer 7: 819-822.

Hemann MT, Bric A, Teruya-Feldstein J, Herbst A, Nilsson JA, Cordon-Cardo C, Cleveland JL, Tansey WP, Lowe SW. 2005. Evasion of the p53 tumour surveillance network by tumourderived MYC mutants. Nature 436: 807-811. 
Hwang HW, Wentzel EA, Mendell JT. 2009. Cell-cell contact globally activates microRNA biogenesis. Proc Natl Acad Sci 106: 7016-7021.

Inomata M, Tagawa H, Guo YM, Kameoka Y, Takahashi N, Sawada K. 2009. MicroRNA-17-92 down-regulates expression of distinct targets in different B-cell lymphoma subtypes. Blood 113: 396-402.

Johnson SM, Grosshans H, Shingara J, Byrom M, Jarvis R, Cheng A, Labourier E, Reinert KL, Brown D, Slack FJ. 2005. RAS is regulated by the let-7 microRNA family. Cell 120: 635647.

Kim VN, Han J, Siomi MC. 2009. Biogenesis of small RNAs in animals. Nat Rev Mol Cell Biol 10: 126-139.

Knobbe CB, Lapin V, Suzuki A, Mak TW. 2008. The roles of PTEN in development, physiology and tumorigenesis in mouse models: A tissue-by-tissue survey. Oncogene 27: 5398-5415.

Kota J, Chivukula RR, O'Donnell KA, Wentzel EA, Montgomery CL, Hwang HW, Chang TC, Vivekanandan P, Torbenson M, Clark KR, et al. 2009. Therapeutic microRNA delivery suppresses tumorigenesis in a murine liver cancer model. Cell 137: 1005-1017.

Kumar MS, Erkeland SJ, Pester RE, Chen CY, Ebert MS, Sharp PA, Jacks T. 2008. Suppression of non-small cell lung tumor development by the let-7 microRNA family. Proc Natl Acad Sci 105: 3903-3908.

Lenz G, Wright GW, Emre NC, Kohlhammer H, Dave SS, Davis RE, Carty S, Lam LT, Shaffer AL, Xiao W, et al. 2008. Molecular subtypes of diffuse large B-cell lymphoma arise by distinct genetic pathways. Proc Natl Acad Sci 105: 13520-13525.

Lewis BP, Shih IH, Jones-Rhoades MW, Bartel DP, Burge CB. 2003. Prediction of mammalian microRNA targets. Cell 115: 787-798.

Lewis BP, Burge CB, Bartel DP. 2005. Conserved seed pairing, often flanked by adenosines, indicates that thousands of human genes are microRNA targets. Cell 120: 15-20.

Lu J, Getz G, Miska EA, Alvarez-Saavedra E, Lamb J, Peck D, Sweet-Cordero A, Ebert BL, Mak RH, Ferrando AA, et al. 2005. MicroRNA expression profiles classify human cancers. Nature 435: 834-838.

Miranda KC, Huynh T, Tay Y, Ang YS, Tam WL, Thomson AM, Lim B, Rigoutsos I. 2006. A pattern-based method for the identification of microRNA binding sites and their corresponding heteroduplexes. Cell 126: 1203-1217.

Navarro A, Bea S, Fernandez V, Prieto M, Salaverria I, Jares P, Hartmann E, Mozos A, Lopez-Guillermo A, Villamor N, et al. 2009. MicroRNA expression, chromosomal alterations, and immunoglobulin variable heavy chain hypermutations in Mantle cell lymphomas. Cancer Res 69: 7071-7078.

O'Donnell KA, Wentzel EA, Zeller KI, Dang CV, Mendell JT. 2005. c-Myc-regulated microRNAs modulate E2F1 expression. Nature 435: 839-843.

Ota A, Tagawa H, Karnan S, Tsuzuki S, Karpas A, Kira S, Yoshida Y, Seto M. 2004. Identification and characterization of a novel gene, C13orf25, as a target for 13q31-q32 amplification in malignant lymphoma. Cancer Res 64: 3087-3095.

Robledo C, Garcia JL, Caballero D, Conde E, Arranz R, Flores T, Grande C, Rodriguez J, Garcia E, Saez AI, et al. 2009. Array comparative genomic hybridization identifies genetic regions associated with outcome in aggressive diffuse large B-cell lymphomas. Cancer 115: 3728-3737.

Rossi DJ, Weissman IL. 2006. Pten, tumorigenesis, and stem cell self-renewal. Cell 125: 229-231.

Schmitt CA, Wallace-Brodeur RR, Rosenthal CT, McCurrach ME, Lowe SW. 2000. DNA damage responses and chemo- sensitivity in the E mu-myc mouse lymphoma model. Cold Spring Harb Symp Quant Biol 65: 499-510.

Selbach M, Schwanhausser B, Thierfelder N, Fang Z, Khanin R, Rajewsky N. 2008. Widespread changes in protein synthesis induced by microRNAs. Nature 455: 58-63.

Shan SW, Lee DY, Deng Z, Shatseva T, Jeyapalan Z, Du WW, Zhang Y, Xuan JW, Yee SP, Siragam V, et al. 2009. MicroRNA MiR-17 retards tissue growth and represses fibronectin expression. Nat Cell Biol 11: 1031-1038.

Tagawa H, Seto M. 2005. A microRNA cluster as a target of genomic amplification in malignant lymphoma. Leukemia 19: 2013-2016.

Tagawa H, Karube K, Tsuzuki S, Ohshima K, Seto M. 2007. Synergistic action of the microRNA-17 polycistron and Myc in aggressive cancer development. Cancer Sci 98: 1482-1490.

Takakura S, Mitsutake N, Nakashima M, Namba H, Saenko VA, Rogounovitch TI, Nakazawa Y, Hayashi T, Ohtsuru A, Yamashita S. 2008. Oncogenic role of miR-17-92 cluster in anaplastic thyroid cancer cells. Cancer Sci 99: 1147-1154.

Trotman LC, Niki M, Dotan ZA, Koutcher JA, Di Cristofano A, Xiao A, Khoo AS, Roy-Burman P, Greenberg NM, Van Dyke $\mathrm{T}$, et al. 2003. Pten dose dictates cancer progression in the prostate. PLoS Biol 1: E59. doi: 10.1371/journal.pbio.0000059.

Ventura A, Young AG, Winslow MM, Lintault L, Meissner A, Erkeland SJ, Newman J, Bronson RT, Crowley D, Stone JR, et al. 2008. Targeted deletion reveals essential and overlapping functions of the miR-17 through 92 family of miRNA clusters. Cell 132: 875-886.

Walker JC, Harland RM. 2009. microRNA-24a is required to repress apoptosis in the developing neural retina. Genes \& Dev 23: 1046-1051.

Wendel HG, Malina A, Zhao Z, Zender L, Kogan SC, CordonCardo C, Pelletier J, Lowe SW. 2006. Determinants of sensitivity and resistance to rapamycin-chemotherapy drug combinations in vivo. Cancer Res 66: 7639-7646.

Xiao C, Srinivasan L, Calado DP, Patterson HC, Zhang B, Wang J, Henderson JM, Kutok JL, Rajewsky K. 2008. Lymphoproliferative disease and autoimmunity in mice with increased miR-17-92 expression in lymphocytes. Nat Immunol 9: 405414.

Zamore PD, Haley B. 2005. Ribo-gnome: The big world of small RNAs. Science 309: 1519-1524. 


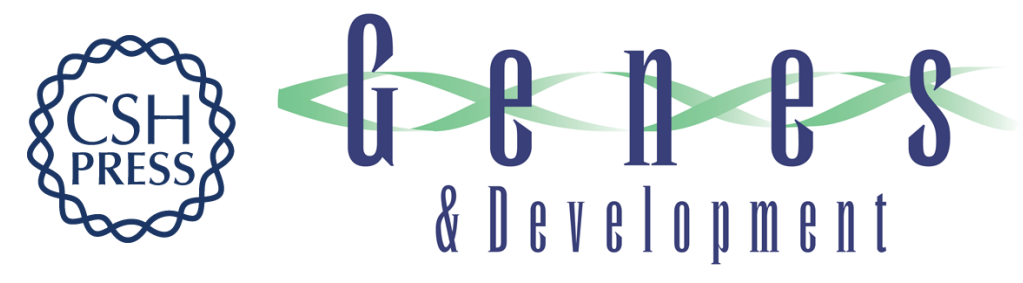

\section{miR-19 is a key oncogenic component of mir-17-92}

Virginie Olive, Margaux J. Bennett, James C. Walker, et al.

Genes Dev. 2009, 23:

Access the most recent version at doi:10.1101/gad.1861409

\footnotetext{
Supplemental http://genesdev.cshlp.org/content/suppl/2009/11/30/23.24.2839.DC1

Material

Related Content Tumorigenicity of the miR-17-92 cluster distilled

Gijs van Haaften and Reuven Agami

Genes Dev. January , 2010 24: 1-4 Genetic dissection of the miR-17<92 cluster of microRNAs in Myc-induced B-cell lymphomas

Ping Mu, Yoon-Chi Han, Doron Betel, et al.

Genes Dev. December, 2009 23: 2806-2811

References This article cites 52 articles, 14 of which can be accessed free at:

http://genesdev.cshlp.org/content/23/24/2839.full.html\#ref-list-1

Articles cited in:

http://genesdev.cshlp.org/content/23/24/2839.full.html\#related-urls

\section{License}

Email Alerting

Receive free email alerts when new articles cite this article - sign up in the box at the top Service

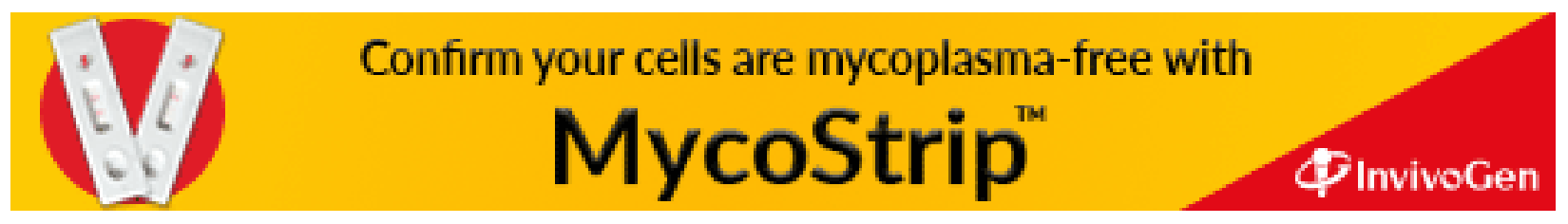

